\title{
Isolation and Molecular Identification of Escherichia coli in Diarrheic Captive Asian Elephants (Elephas maximus) of Tamil Nadu State, India
}

\author{
A. Senthilkumar ${ }^{*}$, M. G. Jayathangaraj ${ }^{2}$, A. Valli ${ }^{3}$, \\ A. Thangavelu ${ }^{4}$, S. Gomathinayagam ${ }^{5}$ and N. Sribalaji ${ }^{6}$ \\ ${ }^{I}$ Tamil Nadu Veterinary and Animal Sciences University, Farmers Training Centre, \\ Theni-625 531, India \\ ${ }^{2}$ Department of Veterinary Clinical Medicine and Therapeutics, \\ Madras Veterinary College, Chennai-600007, India \\ ${ }^{3}$ Institute of Animal Nutrition, PGRIAS, Kattupakkam, Chennai-600007, India \\ ${ }^{4}$ Department of Veterinary Microbiology, ${ }^{5}$ Department of Veterinary Parasitology, Madras \\ Veterinary College, Chennai-600007, India \\ ${ }^{6}$ MSRS, Pottaneri, India \\ *Corresponding author
}

\section{A B S T R A C T}

Keywords

Asian elephantsdiarrhoea- E.coli

Article Info

Accepted:

15 December 2019

Available Online:

20 January 2020
The main objective of the present study was isolation and molecular identification of Escherichia coli in diarrheic captive Asian elephants (Elephas maximus) of Tamil Nadu state. Isolation and identification of E.coli was carried out in both fresh water and dung samples from diarrheic cases of captive elephants $(n=8)$, using standard microbiological culturing method and PCR technique. Out of dung $(n=8)$ and water $(n=8)$ samples, $62.50 \%(n=5)$ of water samples as well as $62.50 \%(n=5)$ of the dung samples were found to be positive for Escherichia coli. On MacConkey Agar, the typical lactose fermenting foul smelling pink coloured colonies indicated the growth of E.coli. In Eosin-Methylene blue agar, the colonies appeared as blackish centres with a metallic sheen indicating the growth of E.coli. Molecular identification of E.coli by Polymerase Chain reaction (PCR), the amplicon size was 476bp.These findings in this study indicated the need for supply of good quality water to the captive elephants, in order to minimize the possible incidences of contamination of Escherichia coli.

\section{Introduction}

Throughout the world, infectious enteritis is the most significant cause of morbidity and mortality in wild animals under captive conditions and it can be caused by many pathogens including viruses, protozoa and bacteria (Izzo et al., 2011). Among bacteria, 
Escherichia coli was one the most important pathogen.(Achá et al., 2004).Water becomes a suitable factor in transmission of infectious enteric diseases and could endanger health and life of humans as well as animals. Coliforms were historically used as indicator of microorganisms to serve as a measure of faecal contamination and thus, potentially of the presence of enteric pathogens in drinking water (Growther et al., 2009).In diarrheic elephants, water and dung samples test is the only way to evaluate the presence of bacteria in drinking water. There is paucity of information related to the examination of drinking water in, used by enteric cases of elephants under captive conditions. Hence analysis of drinking water and dung samples, the incidences of occurrence of $E$. coli organisms in these mega herbivores by culture and / or PCR technique will be much helpful in formulating the suitable management measures that are required for the successful management and preventative measures of captive Asiatic elephants.

\section{Materials and Methods}

Water and dung samples were collected from eight diarrheic elephants during the study period (Table-1).Water samples were collected in $250 \mathrm{ml}$ sterile and clear air tight containers and were subsequently sealed, by using parafilm in order to avoid the contamination. Similarly, fresh dung samples were collected in sterile containers and samples were transported to the laboratory in igloo box containing ice bags in order to maintain the samples as fresh as possible. Isolation and identification of E.coli was carried out in both water and dung samples, using Eosine Methylene Blue agar (Himedia) and MacConkey Agar (Himedia) media and further molecular confirmation by PCR technique.

Isolation of Escherichia coli, the samples streaked over Eosin-Methylene Blue (EMB) agar and Mac Conkey Agar (Himedia) medium followed by incubation at $37^{\circ} \mathrm{C}$ for 24 hrs. DNA was extracted from positive cultures using QIAamp DNA Mini kit (Quiagen) as per manufactures protocol. The extracted DNA template used for confirmation of $E$. coli bacteria by PCR. Primer set designed by Traute Janben (2003) was used for the detection of virulence associated gene of APEC (Avian Pathogenic E. coli) such as Type I Fimbriae (fimC). The primers were procured from Ocimum Biosciences. The amplified PCR products were analysed 1.5\% agarose gel. The details of primers were given below:

\section{Results and Discussion}

Out of the dung $(n=8)$ and water $(n=8)$ samples, pertaining to diarrheic cases examined $62.50 \%(\mathrm{n}=5)$ of water as well as $62.50 \%(\mathrm{n}=5)$ of the dung samples were found to be positive for Escherichia coli as shown in table-2.

\section{Isolation of E.coli bacteria by Culture and PCR technique}

On MacConkey Agar, the typical lactose fermenting foul smelling pink coloured colonies indicated the growth of E.coli.

In Eosin-Methylene blue agar, the colonies appeared as blackish centres with a metallic sheen indicating the growth of E.coli. as shown in Plate 1.Molecular identification of E.coli by Polymerase Chain Reaction(PCR), the amplicon size was 476bp as shown in Plate 3.

Confirmation of Escherichia coli by PCR test carried out in this study was in agreement with the findings of Momtaz et al., (2013) which stated that the Polymerase Chain Reaction assays could be an extremely safe, fast, 
sensitive and specific approach and in order to monitor the safety of the drinking water and in addition to the faecal contamination as well as the contamination of drinking water by sewage also needed to be ruled out. In this regard, the application of PCR assay towards rapid detection of microbes like E.coli was revealed by Moussa et al., (2010).

E.coli in water samples during the present study were in agreement with the findings presented by Growther et al., (2009) and Anwar et al., (2010). In this regard, Smruti and Sanjeeda (2012) opined that the water in nature was seldom totally pure and the most dangerous form of water in nature pollution occurred, when the faecal contaminants like Escherichia coli contaminated the water and the contaminants mixed water resulted in the occurrence of many diseases and hence, the bacteriological quality of drinking water was of paramount significance. Morinigo et al., (1986) also quoted that since the dissemination of faecal microorganisms was incompletely understood, satisfactory methods of control could not be designed and the principal health related risk was quoted to be the presence of faecal pathogenic bacteria which led to the occurrence of enteric diseases.

Encountering, the positivity $(62.50 \%)$ of the pathogenic E.coli organisms investigated in the dung samples as well as water samples of the ailing elephants during the study indicated the need for not only the routine treatment of these mega herbivores but also the need of periodical examination of the drinking water used by the captive elephants reared in temples.

Encountering the Escherichia coli organisms in water samples obtained from the captive elephant-enclosure could be associated mostly with the faecal contamination and hence, water quality could be a compromised one in these cases. In this regard, it was noteworthy to mention the findings of Ramteke et al., (1992) who quoted coliforms as indicators of water quality in India. The encountering of enteric infections in five elephants out of eight animals in this study was supported by Momba et al., (2006) who opined that among the pathogens disseminated in water sources, the enteric pathogens were the ones which were most frequently encountered and the enteric pathogens such as Escherichia coli, Vibrio cholera and Salmonella typhimurium were the usually transmitted ones by the ingestion of contaminated water and foods and the enteric bacteria were reportedly causative agents of various diseases and their complications.

Though no specific strain of Escherichia coli was revealed in this study carried out, it was appropriate to quote the findings of Hunter (2003) who opined that there were enterotoxigenic, enteropathogenic, enterohaemorrhagic, enteroinvasive, enteroaggregative and diffusely adherent strains of Escherichia coli and each type of Escherichia coli caused diarrheal disease through different mechanisms and several of the types caused diarrhoea by the elaboration of one or more toxins and others by some other form of direct damage to the epithelial cells. In this regard, Teplitski (2009) quoted that $E$. coli strain $0157: \mathrm{H} 7$ was found to be the highly virulent. The concurrent finding of Escherichia coli organisms in both dung and water samples in the elephants ailing from diarrhoea in this study was additionally in agreement with the reports furnished by Rompre et al., (2002) who linked the isolation of Escherichia coli with the occurrence of these organisms in drinking water; further, it was stated that though the coliforms were also routinely found in diversified natural environment their presence in the drinking water must be considered as a possible threat or indicative of microbiological water quality 
deterioration. Mehboob and Balkhi (2013) opined that among the enteric pathogens disseminated in water resources, Escherichia coli and other enteric pathogens were frequently encountered and were usually transmitted by the ingestion of contaminated water and foods and their detection in water served as an indicator of its recent contamination with human /or animal excreta.

In connection with the encountering of microbial organisms in water during this study, it appeared to be noteworthy to quote findings of Ramteke et al., (1992) who stated that in the control of diarrhoeal diseases which were responsible for considerable morbidity and mortality, priority must be given to the supply of safe drinking water and this could be ensured only by regular periodical examinations of the drinking water that was supplied to these mega herbivores routinely in all the places or temples that were associated with the management of the captive elephants. The findings in this study indicated the need for supply of good quality water to the captive elephants, in order to minimize the possible incidences of contamination with the microorganisms like Escherichia coli. Further, it is to be remembered that maintenance of hygienic water supply to elephants not only would lead to decrease in the incidences of affection by the micro organisms but also the incidences of affections by other microbes.

Further, it is to be understood that the encountering of Escherichia coli organisms in this study indicated the need for adaptation of effective strategies in order to prevent the transmission of these organisms which have zoonotic significance. Hence, it could be suggested that the dung of elephants especially the sick elephants with history of diarrhoea of dysentery needed to be removed from the surface of the floor of the elephant-enclosure without delay on emergency basis by using gloves and disinfectant solution like glutaraldehyde shall be used for cleaning purposes of floor. In this regard, it was found to be noteworthy to mention the report furnished by Teplitski (2009) who quoted that washing the hands before and after attending to animals was an important one and additionally recommended to wash the surfaces with hot soapy water and fresh solutions of bleach that was prepared according to the manufacturer's instructions and to wear bio- protective footwear over the regular ones.

Table.1

\begin{tabular}{|c|c|c|}
\hline Gene Sequence $\left(\mathbf{5}^{\prime} \mathbf{3}^{\prime} \mathbf{3}^{\prime}\right.$ ) & Amplicon size (bp) & Target Reference \\
\hline FimC F: GGG TAG AAA ATG CCG ATG GTG & $215-235,671-691$ & (Traute J,2003) \\
\cline { 1 - 2 } R: CGT CAT TTT GGG GGT AAG TGC & & \\
\hline
\end{tabular}

Table.2 Places of water and dung samples collected

\begin{tabular}{|c|c|c|c|}
\hline S. No. & Places & \multicolumn{2}{|c|}{ Type of Samples } \\
\hline $\mathbf{1}$ & Ilanji & Dung & Water \\
\hline $\mathbf{2}$ & Tirupugalur & & \\
\hline $\mathbf{3}$ & Virudhunagar & & \\
\hline $\mathbf{4}$ & Nagore & & \\
\hline $\mathbf{5}$ & Tiruvaiyaru & \\
\hline $\mathbf{6}$ & Tirukkurungudi & & \\
\hline $\mathbf{7}$ & Eraittaitirupathi & & \\
\hline $\mathbf{8}$ & Tanjavore & & \\
\hline
\end{tabular}


Table.3 Presence of E.coli in water and dung samples

\begin{tabular}{|c|c|c|c|}
\hline S. No & Place & Water & Dung \\
\hline & & E. coli & E. coli \\
\hline $\mathbf{1}$ & & + & + \\
\hline $\mathbf{2}$ & Virudhunagar & - & - \\
\hline $\mathbf{3}$ & Tirupugalur & - & - \\
\hline $\mathbf{4}$ & Nagore & + & + \\
\hline $\mathbf{5}$ & Tiruvaiyaru & + & + \\
\hline $\mathbf{6}$ & Tirukkurungudi & - & - \\
\hline $\mathbf{7}$ & Erattaitirupathi & + & + \\
\hline $\mathbf{8}$ & Ilanji & + & + \\
\hline
\end{tabular}

Plate.1

\section{Isolation and Identification Of E.Coli}

EMB agar - E.coli

(Colonies with metallic sheen)

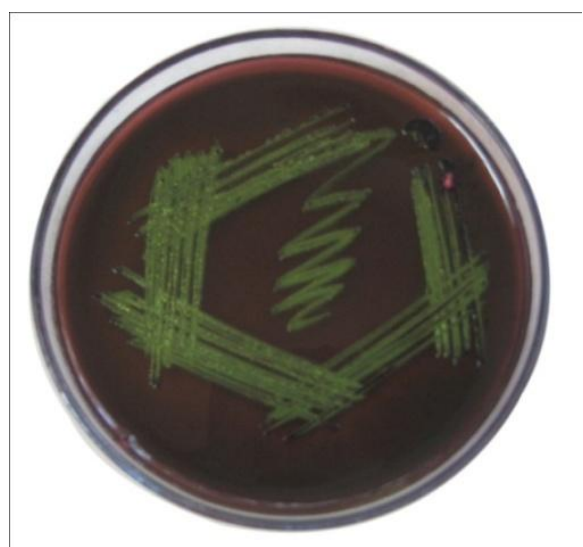

Mac Conkey agar - E.coli (Pink colour colonies)

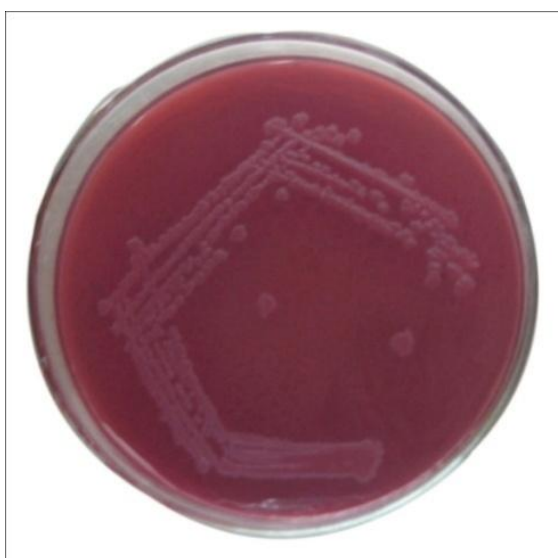




\section{Plate.2}

\section{PCR - Indentification of E.coli}

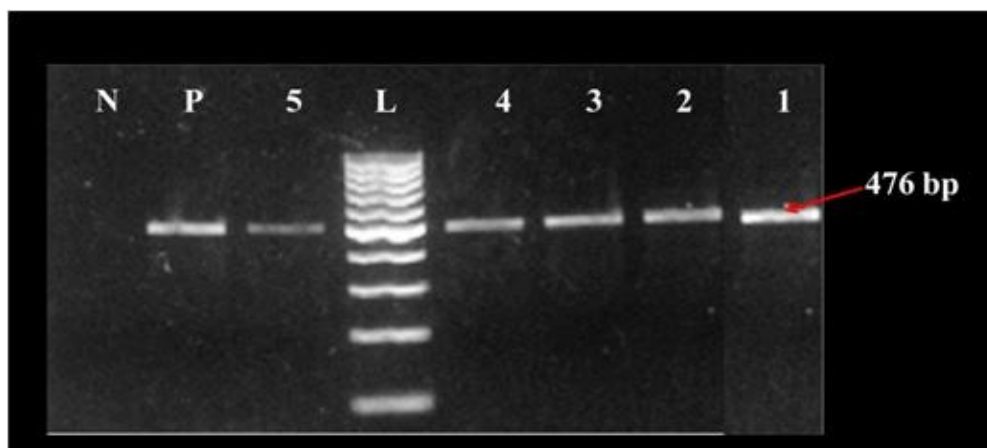

Lane 1, 2, 3, 4, 5-Samples (Fim C gene )

L-DNA Ladder (100bp)

$\mathbf{P}$ - Positive control

$\mathbf{N}$ - Negative control

Additionally, adequate rodent as well as flyproof measures as well as measures to prevent dropping by birds over the water or feeding place should be carried out in the enclosures of elephants accommodating the water or feed storage containers. Since the contaminated animal as well as human wastes were considered as the important reservoirs of pathogens like Escherichia coli organisms, effective steps are required to prevent any dumping of animal as well as human wastes at the enclosure of the captive elephants or near the premises of the elephant enclosure. The education of the care takers of the captive elephants, with regard to the microbiological safety is also suggested as one of the related management measures, pertaining to the prevention of zoonotic diseases.

Hence, it could be finally suggested that the consistent but at the same time, periodical examination of drinking water samples and proper disinfection process of the water storage places or containers or supply routes should be carried out in a systematic manner to prevent the spread of pathogenic microbial organisms like the case with Escherichia coli. However, in this regard it was noteworthy to mention the report furnished by Teplitski (2009) who opined that infected animals with organisms like pathogenic Escherichia coli were not always visibly sick and however, these asymptomatic carrier animals shed billions of virulent organisms in each ounce of their faeces. Hence, in future, it was suggested as one of the management related measures to rule out the presence of these microorganisms, even in the elephants which are not visibly sick.

\section{References}

Acha,S., Kuhn, J.,L., Jonsson, P., Mbaxima, G., Kotouli, M.,Mollby,R.S.,2004. Studies on calf diarrhoea on Mozambique: prevalence of bacterial pathogens. ActaVet.Scand., 45:27-36.

Anwar, M.S., Lateef,S and Siddiqi,G.M., 2010. Bacteriological quality of drinking water in Lahore. Biomedical, 26: 66-69.

Growther, L., Hena,J.V., Sagayaraj,I.A., 
Kishore,K and Kumar,V.A., 2009. Enterotoxigenic E.coli in Coimbatore drinking water. The Internet Journal of Microbiology,7(2):1-4

Hunter, P.R., 2003. Drinking water and diarrhoeal disease due to Escherichia coli. J. Water and Health, 1(2): 65-72.

Izzo,M.M.,Kirkland,P.D.,Mohler,V.L.,Perkins ,N.R.,Gunn,A.A.,House,J.K.,2011.Pre valence of major enteric pathogens in Australians dairy calves with diarrhea. Australians Vet. Journal,89(5):167173.

Mehhoob, M and Balkhi,M.H.,2013. Prevalence of Escherichia coli and Salmonella typhimurium in water samples of Dal Lake. Indian Vet.J. 90(5): 56-58.

Momba, M.N.B., Malakate V.K and Theron,J., 2006. Abundance of pathogenic Escherichia coli, Salmonella typhimuriumand Vibrio cholera in Nkonkobe drinking water sources. $J$. Water and Health. 4(3): 289-296.

Momtaz, H., Dehkordi,F.S., Rahimi,E and Asgarifar,A., 2013. Detection of Escherichia coli, Salmonella species and Vibrio cholera in tap water and bottled drinking water in Isfahan. IranBMC Public Health, 13: 556-562.

Morinigo, M.A., BorregoJ.J and Romero,P., 1986. Comparative study of different methods for detection and enumeration of Salmonella spp. In natural waters. Journal of Applied Bacteriology, 61: 169-176

Moussa, I.M., Gassem,M.A., AI-Doss, A.A.,
Mahomoud,W.A.S

and

Mawgood,A.L.A., 2010. Using molecular techniques for rapid detection of Salmonella serovars in frozen chicken and chicken products collectedfrom Riyadh, Saudi Arabia. African Journal of Biotechnology,9(5): 612-619.

Ramteke, P.W., Bhattacharjee, J.W., Pathak,S.P and Kaira,N.,1992. Evaluation of coliforms as indicators of water quality in India. Indian. $J$. Anim. Sci., 71 (11): 1043-1044.

Rompre, A., Servais,P., Baudart,J., DeRoubin,M and Laurent,P., 2002. Detection and enumeration of coliform in drinking water: current methods and emerging approaches. Journal of Microbiological Methods, 49: 31-54.

Smruti, S and Sanjeeda,I., 2012. Microbiological analysis of surface water in Indore, India. Re. J. Recent Sci., 1: 323-325.

Teplitski, M., 2009. E.coli and Salmonella on animal farms: sources, survival and management. SL-239, Fact sheet of the Soil and Water Science Department, Florida Cooperative Extension Service, Institute of Food and Agricultural Sciences, University of Florida.

Traute, J., 2003. Molecular epidemiological investigations with avian pathogenic $\mathrm{E}$. coli (APEC) field strains and establishment of a diagnostic M.PCR. Thesis submitted to Freie University, Diss. Berlin.

\section{How to cite this article:}

Senthilkumar, A., M. G. Jayathangaraj, A. Valli, A. Thangavelu, S. Gomathinayagam and Sribalaji, N. 2020. Isolation and Molecular Identification of Escherichia coli in Diarrheic Captive Asian Elephants (Elephas maximus) of Tamil Nadu State, India. Int.J.Curr.Microbiol.App.Sci. 9(01): 520-526. doi: https://doi.org/10.20546/ijcmas.2020.901.057 